\title{
EXPERIMENTAL IDENTIFICATION ON NON LINEAR PROPERTIES OF RUBBER MOUNT
}

\author{
Iskandazaqwan Zikrullah Zainudin and Ooi Lu Ean
}

\author{
School of Mechanical Engineering, \\ Universiti Sains Malaysia \\ *Email: ooiluean@usm.my
}

\begin{abstract}
In actual installation, rubber mount are usually excited by different engine force amplitude and frequency. For better characterization of rubber mount, dynamic properties of metal to rubber mount are tested in this paper by using hysteresis loop method. Stiffness and loss factor of rubber mount are calculated from measured hysteresis loop. Experimental works are carried to identify the non-linearity in the amplitude dependent and frequency dependent properties of rubber mount. The s-shaped of hysteresis loop represent as non-linear behavior of rubber mount. The comparison is done for the dynamic properties of rubber mount under different excitation condition. The non-linear behavior of the rubber mount under excitation forced are reported. The result show stiffness change non-linearly according to different amplitude excitation force under different excitation frequency. The observation is significant especially when the excitations force is higher than $5 \mathrm{~N}$ for the small metal to the rubber mounts. However this observation is different compared to the condition where excitation frequency getting higher. The non-linearity in the rubber mount is becoming not significant when the excitation frequency is getting higher.
\end{abstract}

Keywords: Rubber mount, Stiffness, Force amplitude and Non-linearity

\section{INTRODUCTION}

Rubber mounts are commonly used to resolve vibration and noise in any device or machine since 1930[1]. Although several mounting system had been developed from elastomeric mount to hydraulic mount, from passive to active, the rubber mount still been selected to studied due to its compact, cost-effective, maintenance free and provided consistent performance[2][3]. In general, the performance of rubber mounts is influenced by dynamic properties of rubber components[4]. The dynamic properties of rubber mounts include stiffness and loss factor. Stiffness contributed to the energy store in system and damping characteristic is representing energy loss from the system.

Viscoelastic behavior of rubber make rubber mount to deform linearly and nonlinearly under different excitation frequency and amplitude[5]. In order to obtain good description of viscoelastic material, several methods have been carried out. Shimizu et al. (1999) and Fukunaga et al. (2004) modeled viscoelastic materials by the fractional derivative model[6][7]. However, experimental validation was not been carried out during their studies. Lin et al. (2005) and Ooi et al. (2014) were conducted experiment study to evaluate frequency dependent stiffness and frequency dependent lost factor of rubber mount by using impact technique[8][9]. However, the authors were not focused on non-linear region small force excitation was applied in the studied and linear region 
behavior is assumed in the study. The non-linear frequency dependent properties of rubber mount were studied by Sjoberg et al. and Zhu et al. in both experiment and simulation[10][11]. However, authors only focused their studied in low frequency range which is in between $0 \mathrm{~Hz}$ to $100 \mathrm{~Hz}$.

Gade et al. used resonant and non-resonant methods to study complex modulus and loss factor of rubber mount which is shaker is used as excitation source. However, the experiment carried out by authors focused on linear behavior of frequency dependent only[12]. Lin et al. was used impact technique to evaluate the frequency dependent stiffness and damping characteristic of rubber mount. However, the measured force and acceleration responses of the rubber mounts are determined by using Fast Fourier Transform (FFT)[8]. Ooi et al. (2011) further developed the impact technique to determine dynamic transfer stiffness and dynamic driving point stiffness. The difference between dynamic driving point stiffness and dynamic transfer stiffness due to the force applied and measured was considered at different position of the rubber mount[13]. Recently, shaker had been used in the experimental measurement in the low frequency testing on the cable isolators by Guzman et al. to study non-linear behavior of rubber mount. The damping properties are determined by using the shaker test[14]. The shaker excitation method is also applied by Vangipuram et al. in the dynamic characterization of rubber mounts in terms of linear and non-linear behavior.[15].

Hysteresis loop method can be used in several application such as rubber, magnetic field, electrical and so on[10][16][17]. Due to damping rubber material, hysteresis loop are obtained when plotting amplitude of instantaneous force versus instantaneous displacement in a material of all value of time. The linear behavior for dynamic properties of rubber mount will visualize the hysteresis loop in elliptical shape. For non-linear behavior, the shape of elliptical of hysteresis loop will be change to sshape[18]. Hysteresis loop method is proposed here to provide alternative method in characterization of non-linear behavior of rubber mount.

The study presented in this paper will measure the frequency dependent and amplitude dependent stiffness of rubber mount based on hysteresis loop method. The nonlinear behavior is determined within this frequency and amplitude dependent range. The reason to measure frequency dependent and amplitude dependent stiffness at several force and frequency is to study the effect of force and frequency of non-linear properties of rubber.

\section{METHODOLOGY}

\section{Experimental measurement}

The experiment setup used in this study consist of three rubber mounts, an accelerometer, force transducer, $0.9 \mathrm{~kg}$ preload mass, power amplifier, LMS Scadas, stringer and shaker as the controlled excitation force. Rubber mount with diameter of $15 \mathrm{~mm}$ and length of $20 \mathrm{~mm}$ are used. Figure 1(a) shows the experiment setup and the apparatus used in this experiment. The different forces at different frequencies are set on Spectral Testing software and LMS Scadas. LMS Scadas is used as interface with controller to provide signal and collect data. The controller is used to generate voltage sinusoidal wave signal in order to drive the shaker as excitation source. The excitation force and frequency from shaker then will transmitted to the force transducer via stringer. The force transducer is used to measure the input force from the shaker. As Figure 1(b), the accelerometer located below the preload is used to measure the acceleration response 
of engine mounts. The experiment is repeated at differences force excitation of $6 \mathrm{~N}$ and $10 \mathrm{~N}$. The experiment also will repeated with different excitation of frequency. First, the natural frequency of rubber mount is measured by determined the Frequency Response Function (FRF) of the system. Lin et. Al. stated in their studied, the range of natural frequency is determined by defined the half of FRF peak value as stated [8]. Then, the curved of FRF then subdivided into three section: (1) below natural frequency range; (2) within natural frequency range; (3) above natural frequency range.

Below natural frequency range $(0 \leqslant \mathrm{f} \leqslant 90 \mathrm{~Hz})$.

In this experiment, the frequency used for below natural frequency range is $80 \mathrm{~Hz}$.

Within natural frequency range $(90 \leqslant \mathrm{f} \leqslant 140 \mathrm{~Hz})$

Frequency of $100 \mathrm{~Hz}$ is chose for study the stiffness of rubber mount within the natural frequency range

Above natural frequency range $(140 \leqslant \mathrm{f} \leqslant 400 \mathrm{~Hz})$

The frequency used for above natural frequency is $200 \mathrm{~Hz}$. The above natural frequency range is ended at $300 \mathrm{~Hz}$ where the noise contamination in data becomes severe.
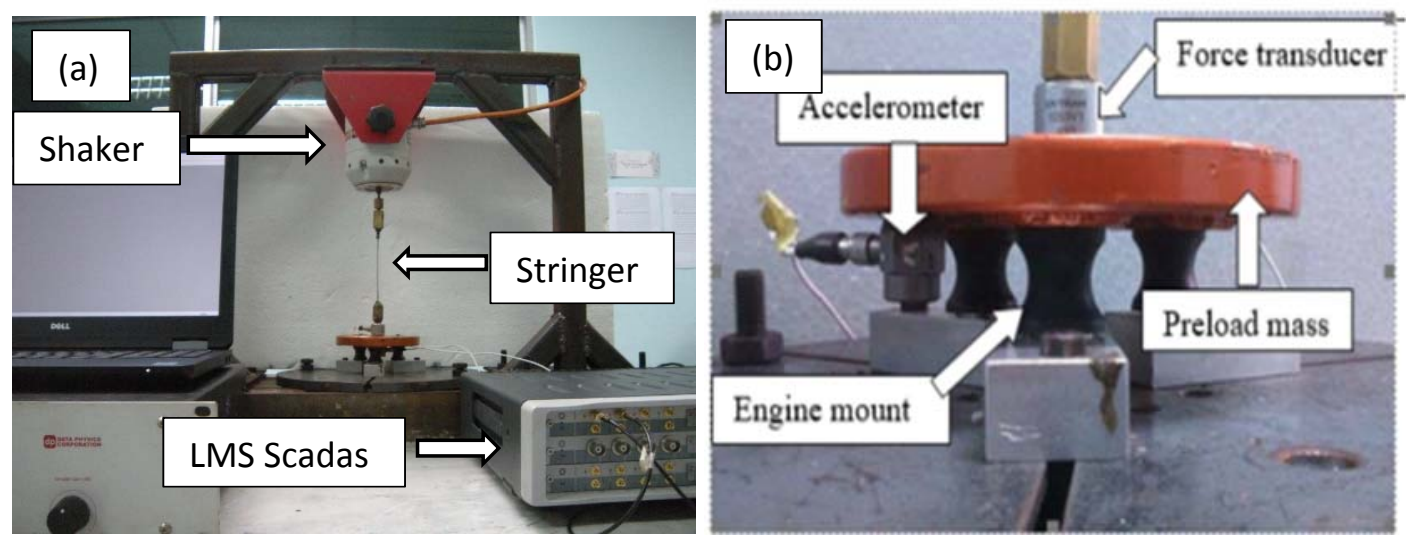

Figure 1. (a) Experiment setup for engine mount and (b) Experiment setup for sine swept method

Hysteresis loops are plotted from the data collected in above setup. Stiffness can be obtained by determine the slope of the loop[10][18]. From the Figure 2, the area of the loop represent as energy lost to the system. The stiffness can be calculated by determine the gradients of each force and displacement from the s-shaped loop. The graph is plotted to determine the stiffness at different gradient for each force and displacement of nonlinear s-shaped loops.

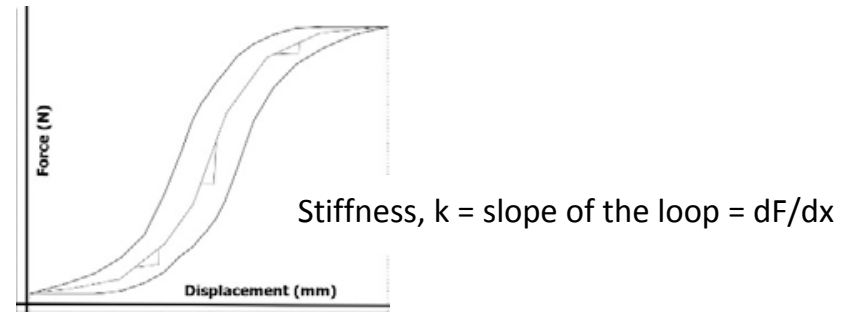

Figure 2: Scematic of Hysteresis loop of rubber mount

RESULTS AND DISCUSSION 
The frequency response function (FRF) of the system is measured. Natural frequency is determined from the peak value of the FRF that is $113.5 \mathrm{~Hz}$. In this study, three frequencies have been chosen to represent three different natural frequency range. For below natural frequency, $80 \mathrm{~Hz}$ is selected. Within the natural frequency, $100 \mathrm{~Hz}$ is selected and for above natural frequency, $200 \mathrm{~Hz}$ is selcted.

Figure 3(a) shows the hysteresis loops that measured with different excitation force. The excitation force applied are 3N, 5N and 10N. From Figure 3(a), the shape of hysteresis loop is s-shape when the force is applied. The s-shape indicated the rubber mount behave non-linearly. Similar finding was reported by Aiken et. al that shows similar shape of hysteresis loops for non-linear behavior in their analytical studied of hysteresis model[19]. Stiffness was calculated as explained in methodology section. Figure 3(b) shows the stiffness calculated based on result from different excitation force but constant excitation frequency. From Figure 3(b), at excitation of 5N, the higher the force the higher the stiffness of rubber mount. The results of $7 \mathrm{~N}$ and $10 \mathrm{~N}$ excitation force shows similar trend with $5 \mathrm{~N}$. At $1 \mathrm{~N}$ of $5 \mathrm{~N}$ excitation force is $133.33 \mathrm{kN} / \mathrm{mm}$, while $1 \mathrm{~N}$ for $7 \mathrm{~N}$ and $10 \mathrm{~N}$ of excitation forces are $109.8 \mathrm{kN} / \mathrm{mm}$ and $90.9 \mathrm{kN} / \mathrm{mm}$ respectively. The percentage different between $1 \mathrm{~N}$ of $5 \mathrm{~N}, 7 \mathrm{~N}$ and $10 \mathrm{~N}$ excitation force is less than $20 \%$. Similar trend of stiffness shows from $2 \mathrm{~N}$ to $5 \mathrm{~N}$ at different of $5 \mathrm{~N}, 7 \mathrm{~N}$ and $10 \mathrm{~N}$ excitation force.

Figure 3(c) shows the hysteresis loops that measured at $100 \mathrm{~Hz}$ but different excitation force. The force applied were $3 \mathrm{~N}, 6 \mathrm{~N}$ and $7 \mathrm{~N}$. The results represented properties of rubber mount within natural frequency range. From Figure 3(c), the loops exhibit linear and the area of the loops are bigger compared to result obtained at $80 \mathrm{~Hz}$ and $200 \mathrm{~Hz}$ as shown from Figure 3(a) and Figure 3(e) respectively. Zainudin et al. (2017) also found the area of the loop become bigger when the excitation force near natural frequency of rubber since more energy loss to the system[20]. Figure 3(c) shows that the linear behavior occur to the system when excitation frequency within the natural frequency since the loops is elliptical shape. Figure 3(d) shows the stiffness of the rubber mount under different excitation force. The change of stiffness is very small when the excitation force change from $1 \mathrm{~N}$ to $7 \mathrm{~N}$. The different is below t $15 \%$ for each force at different excitation force.

Figure 3(e) shows the hysteresis loops that measured at $200 \mathrm{~Hz}$ but different excitation force. Same force level were applied for this frequency range. From the Figure 3(e) the shape of the hysteresis loops is elliptical shape which is linear behavior of the rubber mount system. Similar finding was reported by Ramorino et al. found the linear behavior of rubber mount when excited at higher than natural frequency. Figure 3(f) shows that the increase of the excitation force, the stiffness also increase. The different of stiffness between $3 \mathrm{~N}, 6 \mathrm{~N}$ and $7 \mathrm{~N}$ of excitation force for $1 \mathrm{~N}$ is smaller. The different forces of at $1 \mathrm{~N}$ excitation force is below than $10 \%$. The similar trend were found at different excitation force. 


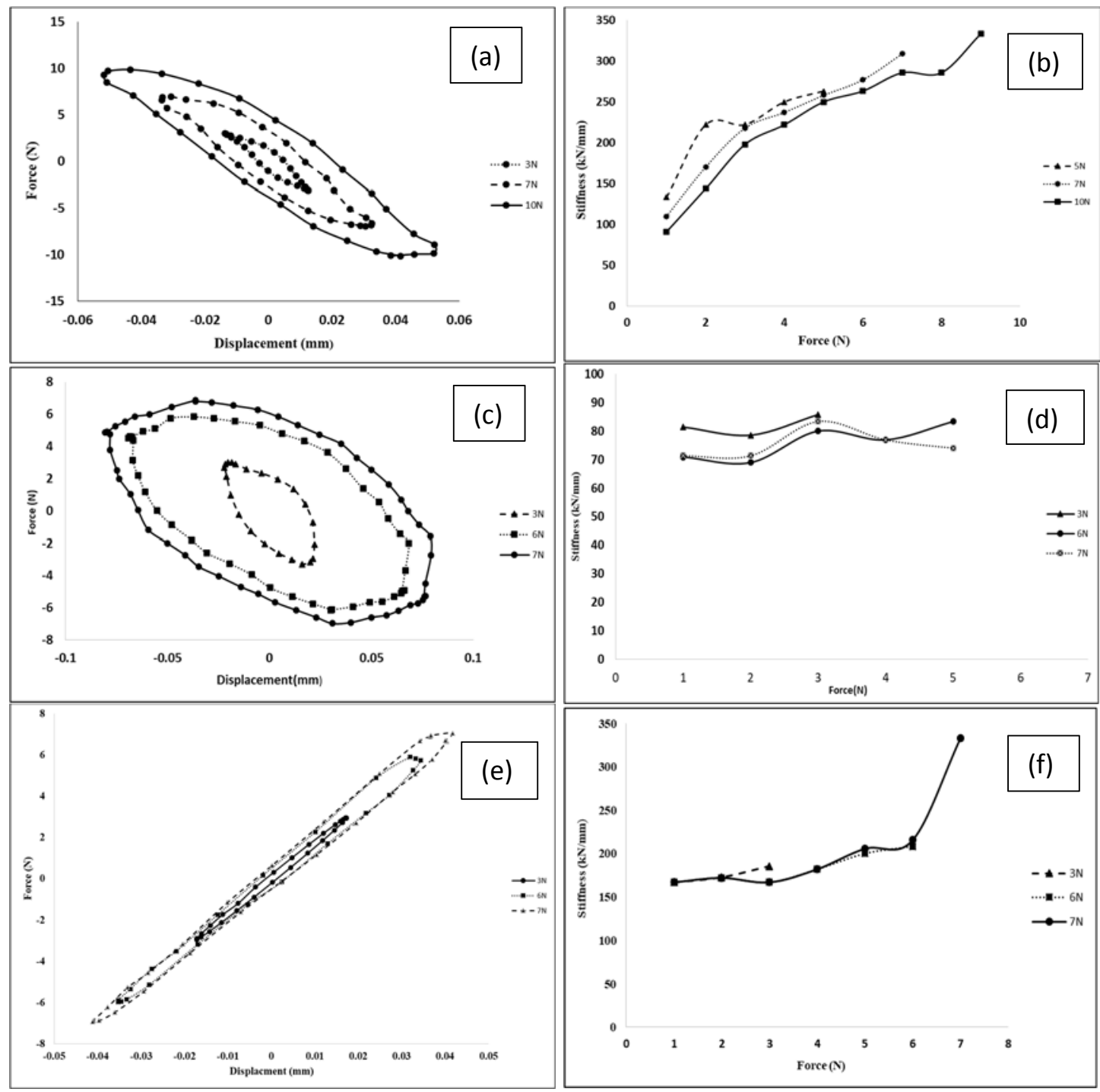

Figure 3(a), (c), (e) Hysteresis loop measures under different force amplitude at $80 \mathrm{~Hz}$, $100 \mathrm{~Hz}, 200 \mathrm{~Hz}$. 3(b), (d), (f) Stiffness under different excitation force amplitude at $200 \mathrm{H}$

The shape of loops at different frequencies are different. For the excitation frequency below and above natural frequency range, the shape of the loops are elliptical. It indicated the loops is linear. For the excitation frequency within natural frequency range, the shape of the loop is s-shape. It indicated that the loops is non-linear. Similar finding were reported by Aiken et. Al. where the shape of non-linear hysteresis loops is s-shaped. From figure 3(a), (c), (e) it is clearly seen that the shape of the hysteresis loop is not perfect. This might be cause by the external energy loss from rig and the connection of screw and nut between preload and rubber mount. The vibration through the rig and the screw and nut will cause energy loss and the losing in the thread of the screw significantly affect the input signal of the system [20].

\section{CONCLUSION}

The measurement using hysteresis loops method is carried out for different frequency and excitation force. The results shows stiffness change non-linearly when excited within natural frequency range. The observation is significant when the excitation force is higher 
than $5 \mathrm{~N}$. However this observation is different compared to the condition where excitation frequency is excited below and above natural frequency range.

\section{ACKNOWLEDGEMENTS}

The author would like to gratefully acknowledge Univsersiti Sains Malaysia (USM) Short Term Grant [account no. 60313028] and Ministry of Higher Education Fundamental Research Grant Scheme [account no. 6071345] for funding the project.

\section{REFERENCES}

[1] H. C. Lord, "Vibration-dampening mounting", United States Patern Office, no. 1778503. 1930.

[2] R. V Schmitt and C. J. Leingang, "Design of Elastomeric Vibration Isolation Mounting Systems for Internal Combustion Engines.” SAE Technical Paper 760431, 1976.

[3] M. W. Sayers and C. Mink, “A Simulation Graphical User Interface for Vehicle Dynamics Models,” SAE Trans., vol. 104, pp. 58-67, 1995.

[4] Y. Yu, N. G. Naganathan, and R. V Dukkipati, “A literature review of automotive vehicle engine mounting systems," Mechanism and Machine Theory, vol. 36, pp. 123-142, 2001.

[5] N. Micali and M. Carlo, "Viscoelastic properties,” Physical Review A, vol. 42, no. 12, 1990.

[6] W. Shimizu, N., \& Zhang, "Fractional calculus approach to dynamic problems of viscoelastic materials,” JSME Int., vol. 4, no. 42, pp. 825-837, 1999.

[7] N. Fukunaga, M., \& Shimizu, “Analytical and numerical solutions for fractional viscoelastic equations,” JSME Int., vol. 47, no. 1, pp. 251-259, 2004.

[8] J. Lin, T. R., Farag, N. H., \& Pan, "Evaluation of frequency dependent rubber mount stiffness and damping by impact test.,” Appl. Acoust., vol. 7, no. 66, pp. 829-844, 2005.

[9] Ooi L. E. and Z. M. Ripin, "Optimization of an engine mounting system with consideration of frequency-dependent stiffness and loss factor,” J. Vib. Control, vol. 22, no. 10, pp. 2406-2419, 2014.

[10] M. M. Sjoberg and L. Kari, “Non-Linear Behavior of a Rubber Isolator System Using Fractional Derivatives,” Veh. Syst. Dyn., vol. 37, no. 3, pp. 217-236, 2002.

[11] P. D. Zhu, S., Cai, C., \& Spanos, “A nonlinear and fractional derivative viscoelastic model for rail pads in the dynamic analysis of coupled vehicle-slab track systems.,” J. Sound Vib., no. 335, pp. 304-320, 2015.

[12] S. Gade, H. Herlufsen, K. Zaveri, and K.-H. H., "Damping Measurements - From Impulse Response Functions - From Resonance and Non-resonance Excitation Techniques,” Brüel Kjaer Tech. Rev., vol. 2, no. 2, p. 50, 1994.

[13] L. E. Ooi and Z. M. Ripin, "Dynamic stiffness and loss factor measurement of engine rubber mount by impact test,” Mater. Des., vol. 32, no. 4, pp. 1880-1887, 2011.

[14] D. F. Guzmán-Nieto, M., Tapia-González, P. E., \& Ledezma-Ramírez, "Low frequency experimental analysis of dry friction damping in cable isolators.," J. Low Freq. Noise, Vib. Act. Control, vol. 4, no. 34, pp. 513-524, 2015.

[15] P. Vangipuram, R., Padmanablan, C., \& Ravindran, "Dynamic characterization of rubber mounts.,” 23rd Int. Congr. Sound Vib., pp. 10-14, 2016.

[16] D. Bachleitner-Hofmann, A., Abert, C., Bruckner, F., Palmesi, P., Satz, A., \& Suess, "Unexpected width of minor magnetic hysteresis loops in nanostructures," IEEE Trans. Magn., vol. 7, no. 52, pp. 1-4, 2016.

[17] and D. Y. Wei, Jing, Yicheng Zhao, Heng Li, Guobao Li, Jinlong Pan, Dongsheng Xu, Qing Zhao, "Hysteresis analysis based on the ferroelectric effect in hybrid perovskite solar cells.," $J$. Phys. Chem. Lett., vol. 5, no. 21, pp. 3937-3945, 2014.

[18] J. P. Nashif, A. D., Jones, D. I., \& Henderson, Vibration damping. A Wiley-Interscience Publication, 1985.

[19] I. D. Kikuchi, M., \& Aiken, “An analytical hysteresis model for elastomeric seismic isolation bearings,” Earthq. Eng. Struct. Dyn., vol. 2, no. 26, pp. 215-231, 1997.

[20] I. Z. Zainudin, H. A. Darun, and O. L. Ean, "Dynamic Measurement of Engine Mount Properties Using Hysteresis Loop Method,” no. August, 2017. 